\title{
Revitalização linguística do japonês no Brasil
}

\begin{abstract}
A atuação dos retornados brasileiros do Japão como professores de língua japonesa
\end{abstract}

\author{
Leiko Matsubara Morales *
}

\section{Considerações iniciais ${ }^{1}$}

Há cerca de duas décadas, diversos artigos jornalísticos das empresas São Paulo Shinbun e Nikkei ${ }^{2}$ ressaltam a questão do declínio da competência linguística dos descendentes de japoneses. Tal percepção não é um fato novo, pois já vinha sendo objeto de ampla discussão em diversos simpósios sobre o ensino de língua japonesa no Brasil (ALIANÇA CULTURAL BRASIL-JAPÃO, 1979 e 1982).

No que se refere ao ensino de língua japonesa no país, a Segunda Guerra Mundial constitui um divisor de águas. No período pré-Guerra, predominava o monolinguismo japonês, por conta da condição em que estavam assentados os imigrantes, como trabalhadores rurais, sem acesso à escola brasileira e com a ideia de voltar ao Japão. Já no pós-Guerra, inicia-se o período de bilinguismo, com a inserção cada vez maior dos descendentes na escola brasileira e com a língua japonesa passando para a condição de língua de herança (MORIWAKI, 1998 e 1999). Assim, a própria denominação das escolas japonesas de nihongakkô (literalmente, escolas japonesas) passou para nihongogakkô (escolas de língua japonesa), ganhando contornos cada vez mais instrumentais e culturais da língua, na tentativa de transmiti-la aos descendentes.

\footnotetext{
* Docente da Universidade de São Paulo, Departamento de Línguas Orientais, Área de Língua e Literatura Japonesa.
} 
Nas nihongogakkô, o ensino se baseava na vivência diária e não na gramática, nem na conversação. Essas instituições de ensino cumpriram função diferente das escolas brasileiras ao desenvolver atividades culturais japonesas, além de incentivar aulas de música e canto. Muitas vezes, as atividades culturais eram conduzidas por pais e mestres, havendo, ainda, mobilização de toda a associação japonesa local. Essa situação era ideal para o desenvolvimento do bilinguismo, já que havia dois domínios distintos em duas línguas e culturas diferentes, de modo que as crianças aprendiam ambas as línguas pela vivência. Nos finais de semana, as crianças tinham a oportunidade de encontrar todos os membros da comunidade para atividades culturais, esportivas e recreativas. Esse panorama permaneceu até finais da década de 1980.

Para compreender o funcionamento das nihongogakkô, tomamos emprestado o conceito de 'comunidade de prática', de Lave e Wenger (1991), bem como as definições de Eckert e McConnell-Ginet (1992):

Um agregado de pessoas que se unem em torno de um engajamento num esforço coletivo. Maneiras de fazer as coisas, maneiras de falar, crenças, valores, relações de poder; em suma, práticas que emergem no decorrer desse esforço mútuo (1992, p. 464). (Tradução nossa).

A existência das nihongogakkô era crucial e indispensável para a permanência da comunidade; as escolas eram importantes lugares de convivência, reunindo gerações. Ainda conforme Lave e Wenger, a existência da escola é, entre outras coisas, o resultado de um esforço coletivo dos membros da comunidade que partilham valores e crenças.

Nesse contexto, a figura do professor de japonês era importante, já que teoricamente seria uma força propulsora para o bom andamento da escola. Contudo, ele nem sempre era reconhecido profissionalmente, entre outros motivos, porque o seu empenho ficava diluído no meio dos trabalhos voluntários dos membros da comunidade.

Para o bom êxito das nihongogakkô, havia um firme tripé de sustentação: a participação dos pais, dos professores e dos próprios alunos. Esse apoio começa a desmoronar com a integração cada vez maior dos descendentes à sociedade brasileira e com a consequente perda linguística, intensificada pelo movimento migratório decasségui, que, num primeiro momento, causou o êxodo de isseis ${ }^{3}$, e, a seguir, de descendentes nisseis ${ }^{4}$ e sanseis ${ }^{5}$ para o Japão (décadas de 1980 e 1990, respectivamente).

Comparando os dados numéricos, a estimativa de crianças brasileiras na faixa de 0 a 14 anos registradas nas cidades japonesas em 1990 era de 2.682; sendo que em 1992, esse número tinha subido para 12.682. A explicação é que, em junho de 1990, foi promulgada a reforma da Lei de Imigração Japonesa, fato que desencadeou a entrada de brasileiros, acompanhados de suas famílias (YAMAMOTO, 2001 e URANO, 2002). Desde então, vinte anos se passaram, e a 
crise gerada pela quebra do banco Lehman Brothers, em 2008, forçou o retorno de brasileiros, trazendo à tona suas vulneráveis condições de trabalho. Cerca de 70 mil pessoas retornaram em 2010, das quais, até o final do mês de março do mesmo ano, 20.693 usaram o subsídio de ajuda oferecido pelo governo japonês para o retorno ao país ${ }^{6}$. Nesse contexto, explica-se o aumento de retornados adultos jovens na companhia de seus pais, estes muitas vezes com idade para se aposentar. Alguns desses jovens alegaram também problemas na continuidade dos estudos, preferindo fazer o curso superior no Brasil.

\section{Perfil dos professores e língua de aquisição}

Fazendo um breve retrospecto histórico, em 1963, 56\% dos professores eram nativos que tinham chegado ao Brasil no período pré-Guerra, $36 \%$ eram nativos do pós-Guerra, e 5,1\% eram nisseis, grupo este formado exclusivamente de mulheres. Na época, o universo de professores de japonês era de 336 pessoas, enquanto o de alunos era de 14.829 (FEDERAÇÃO DAS ESCOLAS DE ENSINO JAPONÊS NO BRASIL, 1966). Em 2004, essa realidade já se configurava de maneira diferente, com cerca de 1.200 professores e 20.000 alunos (FUNDAÇÃO JAPÃO, 2006). Há, no entanto, uma diferença qualitativa, se compararmos a época atual com a década de 1960, quando a esmagadora maioria dos professores conduzia as aulas em sistema de classes multisseriadas, com crianças de faixas etárias e nível de conhecimento linguístico diversos, com funcionamento diário nos dois períodos alternativos à escola brasileira - o que pressupõe uma jornada longa de trabalho, além das atividades culturais e recreativas que se estendiam até nos finais de semana.

A despeito das mudanças trazidas pelo tempo, esse tradicional costume permanece nas nihongogakkô, e a comunidade espera participação dos professores. De modo geral, atualmente, há maior flexibilização nos horários e opções diversificadas de instituições de ensino; porém, isso só ocorre em grandes capitais como São Paulo, visto que no interior, as mudanças são lentas.

Apresentamos, a seguir, o perfil dos professores, segundo a ascendência (tabela 1) e formas de aquisição da língua, para ilustrar a predominância de nativos e descendentes (tabela 2).

\section{Tabela 1}

\begin{tabular}{|l|c|c|}
\hline Ascendência do professor & & \\
\hline Mestiços & 1 & $0,1 \%$ \\
\hline Não descendentes & 13 & $2 \%$ \\
\hline Não especificado & 43 & $7 \%$ \\
\hline Nativos e descendentes & 587 & $91 \%$ \\
\hline TOTAL & 644 & $100 \%$ \\
\hline
\end{tabular}

Fonte: CBLJ / Centro Brasileiro de Língua Japonesa - Guia Escolar 2004 
Tabela 2

\begin{tabular}{|l|r|r|}
\hline \multicolumn{2}{|l|}{ Tipo de aquisição da língua japonesa } & 257 \\
\hline Língua de Herança (descendentes; japonês como L2 ${ }^{7}$ em comunidade) & 248 & $40 \%$ \\
\hline Primeira língua (L1) ${ }^{\text {(nativos japoneses) }}$ & 97 & $15 \%$ \\
\hline Não Especificado & 20 & $3 \%$ \\
\hline Língua Estrangeira & 4 & $1 \%$ \\
\hline Retornados brasileiros (kikokushi) & 626 & \\
\hline TOTAL & \\
\hline
\end{tabular}

Fonte: Centro Brasileiro de Língua Japonesa - Censo para certificação de Professores 2004-2005.

Podemos dizer que, até o ano de 2004, o perfil predominante ainda era de nativos e descendentes (91\%). No caso dos descendentes, a aquisição da língua foi por meio natural, como língua de herança $\left(\mathrm{LH}^{9}\right)$, em casa ou na comunidade, e não como LE $^{10}$ No referido ano, os professores retornados constituíram apenas $1 \%$ do total, mas esse número vem crescendo, como se pode observar no quadro a seguir:

Tabela 3 - Perfil dos inscritos no Curso de Formação de Professores de Língua Japonesa do CBLJ - Centro Brasileiro de Língua Japonesa (2006 a 2010).

\begin{tabular}{|c|c|c|c|c|c|}
\hline Geração & 2006 & 2007 & 2008 & 2009 & 2010 \\
\hline Isseis (old comers) ${ }^{11}$ & 2 & 3 & 4 & 3 & 2 \\
\hline Nisseis & 2 & 4 & 5 & 5 & 5 \\
\hline Sanseis & 2 & 2 & 2 & 2 & 5 \\
\hline Yonseis & 1 & 0 & 0 & 0 & 0 \\
\hline Não-descendentes & 1 & 1 & 1 & 0 & 0 \\
\hline New comers ${ }^{12}$ & 2 & 0 & 0 & 0 & 0 \\
\hline Retornados & 3 & 2 & 3 & 1 & 5 \\
\hline Não respondidos & & & 1 & 2 & 1 \\
\hline Total & 13 & 12 & 16 & 13 & 18 \\
\hline Decasséguis & & & 1 & 4 & 2 \\
\hline
\end{tabular}

Fonte: Centro Brasileiro de Língua Japonesa (2010)

\section{Tipos de aquisição de língua e possíveis efeitos didáticos}

Em escala mundial, de acordo com os dados da Fundação Japão (2006), $29,8 \%$ dos professores de japonês eram nativos; em 2004/2005, a porcentagem de professores no Brasil era de $40 \%$ e, se somados os descendentes, cuja maioria havia adquirido o japonês na forma de aquisição natural, chegava-se a $81 \%$ do total. Muito erroneamente, acredita-se que a fluência de um nativo garante um bom profissional de LE, mas é imprescindível que sejam desenvolvidas habilidades didáticas por parte de tais professores. Desses, muitos acreditam poder transferir 
a sua própria experiência de aprendizado ao exercício da docência, sem terem de passar por cursos de desenvolvimento de habilidades que gerem reflexões sobre o processo de ensino e aprendizagem de LE.

\section{Comunidade de professores de japonês do Brasil}

Ao esmiuçar a comunidade, vemos que, grosso modo, os nativos old comers (isseis) e, algumas vezes, os descendentes (nisseis e sanseis), eventualmente, usam de forma indiscriminada a variedade linguística Koroniago ${ }^{13}$. Por outro lado, os descendentes bilíngues fazem code-switching ${ }^{14}$ em sala de aula, e também produzem "erros" interlinguísticos. Ocorrências desse tipo também podem ser observadas nos professores não descendentes (MORALES, 2009). Não questionamos o valor das variedades linguísticas em si; mas salientamos a necessidade de reconhecê-las nas dimensões intra e interlinguísticas, com o intuito de que o professor - como um bom profissional de ensino de LE e/ou L2 - saiba empregá-las, visando a um melhor efeito comunicativo em situação real, além de orientar os alunos sobre o cumprimento da função social da linguagem, para que eles não sejam estigmatizados pelo uso de determinadas variedades em contextos diferentes.

\section{Método de coleta}

Realizamos entrevistas qualitativas com três informantes, em situação de informalidade, que foram gravadas em IC recorder e, posteriormente, transcritas. Para obter maior entrosamento entre os participantes da pesquisa, no sentido de coletar dados mais espontâneos, pedimos que as informantes P2 e P3 comparecessem juntas à entrevista, e P1 viesse sozinha, pois ela já conhecia a entrevistadora, de quem havia sido aluna. Todas as entrevistas foram feitas em um café, em clima de descontração. Quanto à avaliação da competência linguística, não Ihes foi aplicado nenhum tipo de prova ou teste de língua; baseamo-nos em depoimentos individuais de autoavaliação para evitar constrangimento e, ao mesmo tempo, poder medir o nível de percepção que cada uma tinha sobre suas habilidades linguísticas.

\section{Perfil das informantes}

Não foi nosso objetivo fazer qualquer distinção de gênero, mas, coincidentemente, somente as mulheres atenderam à nossa solicitação. São três jovens com idade entre 22 e 27 anos, com períodos similares de permanência no Japão, mas com diferenças em relação à idade quando da ida ao Japão e ao apoio recebido pelas respectivas famílias. Todas elas trabalhavam, no momento da entrevista, como professoras de japonês em diferentes instituições da cidade de São Paulo.

Em destaque, itens que julgamos importantes do ponto de vista da formação bilíngue e que apresentamos no quadro-sinopse: 


\begin{tabular}{|l|l|l|l|l|l|l|l|}
\hline & Geração & $\begin{array}{l}\text { Idade } \\
\text { atual }\end{array}$ & $\begin{array}{l}\text { Perma- } \\
\text { nência } \\
\text { no Japão } \\
\text { (anos) }\end{array}$ & $\begin{array}{l}\text { Idade } \\
\text { de } \\
\text { ida ao } \\
\text { Japão }\end{array}$ & $\begin{array}{l}\text { Formação } \\
\text { acadêmica }\end{array}$ & $\begin{array}{l}\text { Motivação } \\
\text { para estudo da } \\
\text { língua portu- } \\
\text { guesa }\end{array}$ & $\begin{array}{l}\text { Tempo de } \\
\text { retorno ao } \\
\text { Brasil: } \\
\text { Ago/2010 }\end{array}$ \\
\hline P1 & $\begin{array}{l}\text { yonsei } \\
\text { (4⿳亠口冋 geração) }\end{array}$ & 23 & 12 & 3 & $\begin{array}{l}\text { 2‥ Ano de } \\
\text { Letras }\end{array}$ & $\begin{array}{l}\text { cursinho } \\
\text { mãe e irmã }\end{array}$ & há 8 anos \\
\hline P2 & $\begin{array}{l}\text { sansei } \\
\text { (3a geração) }\end{array}$ & 22 & 11 & 4 & $\begin{array}{l}\text { aulas de } \\
\text { formada em } \\
\text { economia } \\
\text { cursinho, } \\
\text { amigos }\end{array}$ & há 7 anos \\
\hline P3 & Mestiça & 27 & 15 & 8 & $\begin{array}{l}\text { supletivo } \\
\text { completo } \\
\text { no Japão }\end{array}$ & $\begin{array}{l}\text { 2 gestações e } \\
\text { o crescimento } \\
\text { dos filhos }\end{array}$ & há alguns \\
meses
\end{tabular}

Tabulação nossa.

\section{Modo de aquisição das línguas}

Relativamente ao modo de aquisição das línguas, cabe destacar alguns pontos: P3 foi a informante que passou mais vezes por mudanças de ambiente linguístico, e teve menos assistência da família durante o "período crítico"15. Seu histórico de transição revela que aos 8 anos foi levada pela primeira vez ao Japão, quando ocorre a mudança do idioma português para o japonês; a segunda mudança foi aos 11 anos, ainda no Japão, quando foi transferida para a escola brasileira, onde só se falava português; nova mudança acontece aos 15 anos, quando voltou temporariamente ao Brasil; a quarta e última mudança foi aos 27 anos, ocasião em que voltou definitivamente ao Brasil. É certo que mudanças linguísticas podem até ser um fator positivo na vida de uma pessoa, desde que ela tenha assistência e acompanhamento da família e da escola; porém, no caso em estudo, P3 conta que passou por maus tratos na escola japonesa (ijime) e teve um período de silêncio (cuja duração não soube precisar), durante o qual não conseguia se comunicar com professores ou colegas.

O impacto negativo das mudanças linguísticas pode ser menor, se elas ocorrerem em idade mais tenra. Foi o que aconteceu com P1 e P2, que não sentiram nenhuma dificuldade nas creches japonesas. Aliás, estudos feitos no Japão salientam que as creches daquele país são espaços que propiciam maior integração social (KAWAMURA, 1995). Trata-se, contudo, de uma situação de bilinguismo subtrativo, uma vez que no ambiente das creches, a criança será monolíngue em japonês, em detrimento do português, sua L1. De fato, quando as informantes voltaram ao Brasil, tiveram de estudar o português como se fosse uma LE. Para que ocorresse um ensino bilíngue, seriam necessárias políticas públicas de manutenção da L1 das crianças. Poucos pesquisadores, como Mcmahill (2010), destacam a importância do ensino da língua portuguesa nas escolas japonesas. 


\section{Aportes teóricos para esta pesquisa}

Do ponto de vista da aquisição de LE, diversos trabalhos discutem os efeitos do ambiente linguístico para se obter uma melhor aquisição da língua-alvo: o ensino em sala de aula e em ambiente natural, assim como a importância de ter os dois ambientes (MORIYAMA et al., 2008). Diversos trabalhos nesse sentido foram discutidos na década de 1980, como por exemplo: Krashen (1982); Pica (1983); Long (1980); e Lightbown (1983). Há ainda fatores sócio-históricos, geográficos, emocionais, linguísticos e culturais. $O$ fato é que a inserção das crianças em processo de migração desencadeia uma série de estratégias para a sua adaptação em um novo ambiente linguístico e cultural, não só de ordem linguística, mas também psicológica; e nem sempre os professores de escolas normais que estão em contato com essas crianças, possuem conhecimento de ensino como LE.

Cabe esclarecer que para realizar a referida pesquisa, é legítimo buscar apoio em estudos de Cummins (1987 e 1991) com filhos de imigrantes no Canadá, dentro do contexto escolar do país-hospedeiro. Esse autor estabeleceu uma diferença entre as noções de BICS (Basic Interpersonal Communicative Skills) e de CALP (Cognitive Academic Language Proficiency), durante o processo de adaptação linguística em contexto de migração. A primeira trata da linguagem interpessoal e a conversação do dia a dia para resolver questões do cotidiano; enquanto a segunda constitui a linguagem acadêmica específica para ser usada em assuntos da escola, e trata de procedimentos intelectuais que propiciarão o desenvolvimento cognitivo da criança. Segundo observações empíricas, o citado pesquisador constatou que no que se refere à BICS, leva-se de dois a três anos para a criança adquirir em contato com o novo ambiente lingüístico; enquanto em relação à CALP, a criança pode levar de cinco a sete anos para se desenvolver como um nativo (CUMMINS, 1980). Ou seja, se uma criança é deslocada do seu contexto linguístico e passa a usar uma língua diferente, é preciso que os adultos ao seu redor tenham compreensão desses conceitos e percebam que nem sempre as duas competências caminham lado a lado; além de também ser necessário evitar comparar a criança com monolíngues da mesma faixa etária, respeitando-se, assim, o tempo de que elas necessitam para chegar a um nível linguístico condizente e esperado.

\section{Estágio de bilinguismo das informantes}

Segundo as informantes $\mathrm{P} 1$ e $\mathrm{P} 3$, o japonês é a língua dominante, já que elas preferem ler textos jornalísticos e/ou dissertativos nessa língua; porém, em alguns casos, dependendo do nível de familiaridade com o assunto, elas chegam a usar 'estratégias de comunicação', como o empréstimo de expressões em língua portuguesa, como veremos adiante. P2 considera-se fluente nas duas línguas e não incide em alternância de código linguístico. Entre as informantes, ela é a única que preserva o discurso formal, usando adequadamente o marcador de polidez (desu e masu), atuando em situações sociolinguísticas e interpessoais. 


\section{Redes de apoio}

Mapeamos as redes de apoio de modo a evidenciar a assistência da família, marcando, assim, as condições de estudo e recursos materiais e pessoais que ficaram disponíveis para as informantes, ao longo da vida escolar no Japão e no Brasil.

\begin{tabular}{|c|c|c|c|c|c|}
\hline & $\begin{array}{l}\text { Teve motivação para } \\
\text { o estudo da língua } \\
\text { portuguesa? }\end{array}$ & \begin{tabular}{|l|} 
Material de \\
Apoio
\end{tabular} & $\begin{array}{l}\text { Escolas } \\
\text { especiais }\end{array}$ & $\begin{array}{l}\text { Meios de } \\
\text { superação }\end{array}$ & Influências \\
\hline P1 & \begin{tabular}{|l|} 
Sim, pois sempre \\
queria voltar a \\
morar no Brasil, mas \\
as críticas negativas \\
dos parentes \\
foram bastante \\
contundentes.
\end{tabular} & \begin{tabular}{|l|} 
Livros que \\
a sua tia, \\
professora \\
de uma \\
escola \\
pública, \\
conseguiu \\
providenciar \\
para \\
estudar.
\end{tabular} & $\begin{array}{l}4 \text { anos de } \\
\text { cursinho, que } \\
\text { a ajudaram } \\
\text { a gostar de } \\
\text { estudar, } \\
\text { facilitando- } \\
\text { Ihe o } \\
\text { entendimento } \\
\text { do conteúdo. }\end{array}$ & \begin{tabular}{|l|} 
Amigos \\
do colégio \\
ajudavam na \\
prova. Incentivo \\
da família, por \\
meio de apoio \\
psicológico e \\
também custeio \\
do cursinho.
\end{tabular} & Parentes e pais \\
\hline P2 & $\begin{array}{l}\text { Não muito; a } \\
\text { vontade de estudar } \\
\text { com seriedade } \\
\text { só veio durante } \\
\text { o período de } \\
\text { preparação para o } \\
\text { vestibular. }\end{array}$ & \begin{tabular}{|l|} 
Os livros \\
eram da \\
escola, ou \\
adquiridos \\
com recurso \\
próprio.
\end{tabular} & $\begin{array}{l}\text { Colégio } \\
\text { particular, com } \\
\text { cursinho no } \\
\text { último ano do } \\
\text { colégio; mas o } \\
\text { que realmente } \\
\text { a ajudou } \\
\text { foi resolver } \\
\text { estudar } \\
\text { seriamente. }\end{array}$ & $\begin{array}{l}\text { Apenas copiava } \\
\text { o conteúdo } \\
\text { estudado, } \\
\text { mesmo sem } \\
\text { compreender } \\
\text { o que estava } \\
\text { escrevendo. }\end{array}$ & $\begin{array}{l}\text { Amigos e colegas } \\
\text { da escola. }\end{array}$ \\
\hline P3 & $\begin{array}{l}\text { Não apresentou } \\
\text { nenhuma resposta } \\
\text { para esta pergunta; } \\
\text { contudo, seu } \\
\text { empenho em } \\
\text { aprender a língua } \\
\text { japonesa estava } \\
\text { diretamente ligado } \\
\text { ao trabalho que } \\
\text { fez de intérprete } \\
\text { durante o período } \\
\text { em que esteve } \\
\text { desempregada no } \\
\text { Japão. }\end{array}$ & $\begin{array}{l}\text { Não } \\
\text { comentou. }\end{array}$ & $\begin{array}{l}\text { Supletivo no } \\
\text { Japão (3 a } 4 \\
\text { meses). }\end{array}$ & \begin{tabular}{|l|} 
Não comentou \\
a respeito; não \\
sentiu tanta \\
necessidade de \\
estudar no Japão \\
e no Brasil.
\end{tabular} & $\begin{array}{l}\text { Aparentemente, } \\
\text { nenhuma. }\end{array}$ \\
\hline
\end{tabular}


As informantes P1 e P2 tiveram bastante apoio da família; ao contrário de P3, que não teve praticamente nenhum.

A informante P2, que recebeu maior assistência, contou sempre com serviços profissionais de professores particulares para acompanhar os estudos; além disso, o chefe de sua família viajou ao Japão como executivo de uma empresa, em situação confortável em termos financeiros e sociais, diferentemente do que ocorre na maioria das famílias de decasséguis.

P1 não percebeu diferença na mudança linguística, pois foi aos 4 anos de idade para o Japão, e aprendeu facilmente a língua, ao ingressar numa creche japonesa. Sua primeira experiência com L2 ocorreu no retorno ao Brasil, aos 13 anos de idade, quando teve de aprender uma língua nova. Primeiramente, ela foi matriculada numa escola estadual, sem receber atenção especial por ser estrangeira, e só se interessou pelos estudos quando ingressou no curso preparatório para o vestibular, no qual "os professores explicavam bem, tinham vontade de fazer a gente entender". Com esse grande ponto de inflexão, ela passou a realmente gostar de estudar, empenhando-se, inclusive, em ser aprovada no curso de Letras da Universidade de São Paulo (USP). Sua adaptação à escola brasileira foi um pouco difícil no começo, porque ela era considerada "ingênua" pelos colegas brasileiros, sendo frequentemente alvo de gozações, ao não entender as brincadeiras e nem as piadas. Ao mesmo tempo, porém, ela teve amigos que a ajudaram na fase de adaptação: "eram amigos que faziam prova no meu lugar", "passava a folha de resposta inteirinha respondida de questões de história". Durante o curso preparatório para o vestibular, ela só conseguiu enfrentar mais um ano de curso graças ao apoio da mãe e da irmã, pois, no total, foram quatro anos frequentados.

P3 relatou que não cursou o ensino médio, e só frequentou um curso supletivo no Japão; porém, mesmo sendo aprovada, considera que esse curso "não foi suficiente para aprender todo o conteúdo que deveria ter estudado". Ela não relatou nenhum tipo de esforço para estudar, e afirmou que isso se devia ao fato de se sentir "protegida" por ser estrangeira e os professores japoneses não exigirem dela os mesmos resultados. Durante a entrevista, porém, ela demonstrou alto grau de interesse, e seu nível de concentração aumentou ao falar de assuntos de trabalho: começara a trabalhar cedo, aos 17 anos; sendo que durante o período de quase um ano em que ficou desempregada, manteve-se com trabalhos de intérprete, acompanhando gestantes a consultórios médicos, sabendo, assim, dizer vários termos da área de ginecologia e obstetrícia, demonstrando dominar o jargão técnico da área, pouco usado na linguagem do dia a dia.

\section{Pontos de inflexão}

P1 sentia-se muito injustiçada, quando os parentes com os quais morava faziam críticas sobre o seu português, em relação a erros de conjugação e falta de marcação do plural. Muitas vezes, eles lhe dirigiam palavras desencorajadoras 
quanto à sua obstinação em prestar o vestibular da FUVEST (Fundação Universitária para o Vestibular). Tais críticas passaram a ser uma motivação para as quatro tentativas de passar nesse certame. Depois de ter ingressado na carreira desejada, podemos dizer que a sua batalha continua com a produção de textos dissertativos, como também demonstra ter dificuldades para ler textos teóricos que requerem maior reflexão. Houve, inclusive, uma ocasião em que P1 não conseguiu decodificar os caracteres japoneses, o que parece tê-la constrangido a ponto de pedir à sua orientadora a entrega antecipada do texto para preparar a leitura.

No caso de P2, embora a própria informante não tenha mencionado o fato, parece terem surtido efeito os anos de acompanhamento com professores particulares em casa, e também o fato de ter frequentado colégios particulares. Contudo, ela confessou que nunca sentiu motivação para estudar, e que a mudança só veio ao se sentir desafiada pelos colegas do colégio, que diziam que "não prestariam vestibular fácil como o de Letras, só para dizer que entraram na USP". Assim, apesar de a intenção inicial ser prestar vestibular para Letras, ela mudou para uma carreira mais concorrida (Economia), "para não fazer feio".

P1 e P2 demonstraram que o "desafio" constituiu uma força propulsora para o enfrentamento de suas limitações e o engajamento nos estudos. Já, P3 não esboçou essa preocupação em superar dificuldades provocadas pela língua, mesmo tendo passado por diversas experiências de bullying escolar. Um dado interessante a notar é que P3 parece ter um nível muito alto de resiliência, uma vez que diante das adversidades pelas quais passou, mantevese muito serena. Destaque-se, ainda, que P3, na ocasião em que participou da nossa pesquisa, estava recém-separada do companheiro, pai de seus dois filhos menores. Quando a pesquisadora lhe perguntou sobre como será a educação linguística dos filhos, ela disse que jamais permitiria que seus filhos passassem pelo que ela passou.

\section{Ocorrências Linguísticas}

Em termos de ocorrências linguísticas, podemos apreendê-las por diversos ângulos. Destacamos alguns aspectos merecedores de atenção no âmbito do ensino. P3 foi a que apresentou maior número de ocorrências interlinguísticas, denominadas 'Estratégias Comunicativas' (ECs). Estas são recursos frequentemente utilizados por aprendizes de LE; quando Ihes faltam palavras para se fazer entender, recorrem à L1. Nota-se que o interessante é que, no caso de P3, sua língua dominante é o japonês; no entanto, quando lhe faltam palavras no repertório, ela compensa com a expressão equivalente na língua portuguesa, já que essa é a língua de comunicação entre os membros da família. Para ilustrar o exemplo, apresentamos, a seguir, um fragmento da entrevista; convém afirmar, porém, que tais tipos de ocorrências diferem do que 
os estudos bilíngues denominam de code-switching, uma alternância de códigos típica de bilíngues fluentes, sem quebras de sintaxe, sintagmas, e nem mesmo de unidades lexicais. As palavras que faltavam no transcurso da conversa de P3 eram inseridas em português, para sustentar a comunicação. Essa pode ser uma estratégia comumente usada entre os familiares, o que pode prejudicar a atualização do vocabulário através de novas expressões.

A seguir, apresentamos trechos selecionados: no caso, as palavras 'polícia federal' e 'entrar em greve' são precedidas de larga hesitação, seguida de 'preenchedores de pausa' (anô...), o que reforça a evidência de que ao falar, a entrevistada está em busca de uma palavra, e que por não encontrá-la na língua em uso, ela acaba recorrendo à EC.

Entrevistador: 2003-nen ni Burajiru ni modotte...sorekara, mata, Nihon e?

P3-Ah, sô, shigatsu ni kaetta toki wa, mô sono toki wa ninshin 7-kagetsu de...de, kodomo ga ....ni-san-kagetsu ni nattara mata Nihon ni kaeru kaeru yotei dattandesu kedo, anô, anô, polícia federal toka, zenbu, entrou em greve, e pasupôto ga torenakattashi, watashi no biza ga kirete, Nihon e itta toki mo shita no ko ga issai-han, 2005-nen nni zutto Burajiru ni ite, de, mata, 2005-nen mata, Nihon...2005-nen 2-gatsu, Nihon e itte, de, kotoshi, a, kyonen, 2009-nen ni kaette...

Entrevistador (Tradução): Voltou para o Brasil em 2003 e depois, novamente ao Japão?

P3 - Ah, é, quando voltei em abril, eu já estava com sete meses de gravidez, então, me programei para voltar ao Japão assim que a criança completasse dois ou três meses, bem..., então..., por exemplo, a polícia federal, tudo entrou em greve, e não consegui tirar o passaporte, meu visto expirou; quando fui ao Japão, o filho mais novo já estava com um ano e meio. No ano de 2005, fiquei direto no Brasil, e em 2005, em fevereiro de 2005, fui ao Japão, e este ano, não, ano passado, em 2009, voltei ao Brasil.

As três informantes afirmaram ter tido dificuldades para se adaptar ao novo ambiente linguístico, mas parece haver uma correlação entre o número de erros interlinguísticos e o grau de percepção de suas "falhas linguísticas". Percebemos que em P1 e P2 há um cuidado para falar, um maior controle na exposição de sua fala, talvez, porque a entrevistadora seja professora da Letras, ou porque sabem se tratar de uma pesquisa. A informante P2, por gostar de línguas, ingressou num programa de intercâmbio para estudar inglês no Canadá, o que mais uma vez confirma a importância das decisões pessoais em relação às línguas envolvidas. 
P3 também não conseguiu sustentar uma conversação que requeresse um nível de vocabulário elevado, além de demonstrar que o seu japonês tem uma forte influência da variante dialetal da região de Aichi, perceptível até mesmo aos ouvidos daqueles que não são nativos japoneses.

\section{Escolha da profissão}

Quanto à escolha profissional de ser professor de japonês, P1 e P3 disseram ter escolhido essa carreira porque "era a única coisa que sabia fazer" (P3); ou "era a coisa que mais sabia fazer" (P1). Somente P2 nos contou, em tom cerimonioso, como se estivesse pedindo desculpas, que a escolha foi estratégica, já que havia selecionado "a carreira mais rentável em curto prazo"; além de esta ser "o caminho mais curto para trabalhar com língua", pois o que ela queria de fato fazer era seguir a carreira de tradutora-intérprete, ou em relações internacionais. Das três, P2 é a que usa a língua como instrumento para atingir outro objetivo maior, enquanto P1 e P3 parecem estar "reféns da língua".

Quando pedi para que dissessem qual língua era a dominante, P1 disse que as duas línguas eram fortes. Já, P3 não soube precisar esse ponto, afirmando que não tinha domínio em nenhuma dessas línguas. De acordo com suas palavras, tudo está "na metade do caminho", ou seja, chûtohanpa. Somente P2 nos deu uma descrição precisa e objetiva da sua autoavaliação, relatando que fazia os relatórios e trabalhos da faculdade sem problemas, chegando a avaliar que, em se tratando de relatórios, tinha noção de que o seu português era melhor do que o japonês, pois durante o curso de Economia fazia leituras teóricas e operações linguísticas mais sofisticadas em português. Por sua vez, P1 relatou enfrentar desafios para "adquirir o vocabulário acadêmico para escrever textos dissertativos" - fato esse que veio a ser comprovado, posteriormente, pelas anotações de campo, que apontam muito mais para problemas na estruturação do texto e da sintaxe, do que no vocabulário em si.

\section{Considerações finais}

Foi importante estudar tais perfis, tendo em vista o ensino de língua japonesa, na medida em que esta pode constituir a língua dominante, ou ser uma língua em desenvolvimento. Nesse sentido, com a emergência desse novo perfil - que é diferente dos old comers (isseis) e dos new comers -, os organizadores de cursos de formação devem levar em conta o tipo de aquisição de língua, bem como alguns fundamentos do bilinguismo, como, por exemplo, uma formação linguística fragmentada; além de ainda incorporar questões da variação interlinguística (estratégia comunicativa, code-switching, etc), em vez de restringir-se ao aspecto intralinguístico (registro, aspectos sociolinguísticos), tendo em vista a enorme diversidade que pode ser encontrada em qualquer língua.

Historicamente, por ter sido uma LH, adquirida naturalmente no convívio familiar e comunitário, o idioma japonês não é para muitos uma LE, que requer 
anos de estudo com dedicação e conhecimento de metodologia de ensino e aprendizagem. Isso gera pouca valorização entre a comunidade, para com a figura do professor de nihongogakkô como profissional. O fato é que, com a chegada desses retornados, está havendo uma sensível revitalização do japonês falado no Brasil, que é carente de pessoas com maior fluência, através da atualização do repertório em relação à variante local, e do aporte de informações culturais do dia a dia do Japão.

Em nome da diversidade linguística no Brasil, é importante que o japonês continue a ser ensinado como LE, e que a comunidade nipo-brasileira continue investindo nas condições de trabalho dos professores de japonês, pois só assim conseguiremos atingir um nível mais elevado de profissionalização do professor da nihongogakkô. Não devem ser desperdiçadas as oportunidades que o retorno desses jovens oferece para a revitalização do ensino de língua japonesa no Brasil.

\section{Notas}

1 - A primeira versão deste trabalho foi publicada nos Anais da BRASA (Brazilian Association Studies), em Brasília, em 2011.

2 - Tradicionais veículos de comunicação da comunidade Nikkei em atividade no solo brasileiro, escritos majoritariamente em língua japonesa.

3 - Japoneses nativos; literalmente, primeira geração.

4 - Descendentes de segunda geração.

5 - Descendentes de terceira geração.

6 - Jornal Nikkei, 20.4.2010.

7 - Há uma distinção, na literatura, sobre o ambiente linguístico de uma língua em aquisição. Normalmente, a L2 se refere a uma língua com a qual o aprendiz tem contato no dia a dia, como meio de comunicação, mesmo não sendo a sua primeira língua. É o caso dos brasileiros que estão no Japão, aprendendo o japonês como L2. No presente trabalho, o termo será coextensivo aos descendentes japoneses que vivem no Brasil, em virtude de eles terem crescido em comunidades que tinham o japonês como língua de comunicação, mesmo havendo redução na qualidade dos insumos lingüísticos, se comparados aos do Japão.

8 - A L1 é a língua materna ou nativa de uma pessoa. A L1é a língua que uma pessoa aprende por meio de aquisição natural.

9 - O conceito de Língua de Herança (LH) pode se referir à língua transmitida de pai para filho, em situação de bilinguismo, como língua minoritária frente à língua oficial falada majoritariamente no país em que a criança nasceu, ou para o qual emigrou. No caso em estudo, trata-se de descendentes japoneses, filhos de imigrantes japoneses que nasceram no Brasil, mas que por viverem em comunidade de japoneses, falavam a língua dos ancestrais. $O$ termo pode, ainda, referir-se à primeira língua da criança que se muda para outro país, e que em contato com um novo ambiente linguístico terá de aprender uma nova língua, mas sem deixar de falar a primeira (que, no caso, poderá ser denominada de LH). Assim, o termo é coextensivo àqueles que nasceram no Brasil e aprenderam o japonês num contexto comunitário e familiar, e também àqueles que para cá vieram e trouxeram sua primeira língua. Há vários pontos de intersecção entre LH e L2; enquanto o primeiro tem a possibilidade de realização linguística reduzida por estar em outro país, o L2 é a língua majoritária do novo ambiente lingüístico, e é um termo abrangente para dizer que se trata de uma segunda língua além da primeira.

10 - 0 conceito de língua estrangeira refere-se àquela que é aprendida pelo aluno em situação de sala de aula. Muitas vezes, o estudo se limita à gramática e à conversação funcional em sala de aula, e o aluno não está no país em que se fala essa língua. A língua não é o meio de 
comunicação direto no seu dia a dia, e os insumos linguísticos são controlados, por ocorrerem em ambiente de sala de aula.

11- Em contraste a new comers, costuma-se empregar o termo old comers para os isseis, nativos japoneses que chegaram logo da retomada da imigração pós-Guerra, a partir de 1953 até a década de 1980 .

12- O conceito de new comers pode variar, de acordo com os pesquisadores. No nosso entendimento, ele abrange os nativos que vieram ao Brasil a partir da década de 1990 .

13 - É uma denominação dada à língua japonesa falada no Brasil, com suas variantes em relação ao japonês padrão falado no Japão, por conta dos empréstimos linguísticos, novas criações resultantes do fenômeno de contato linguístico e matizes semânticas. Sobre a variante em questão, os dados linguísticos podem ser conferidos em KUYAMA (1999; 2000) e DOI (2002; 2006; 2009).

14 - Termo usado no bilinguismo, para se referir à mudança de código linguístico que os falantes bilíngues fazem frequentemente ao longo da sua conversação, que pode ser motivada por diversos fatores, tais como: mudança de tópico do assunto, identificação com o interlocutor, situação de informalidade.

15 - Trata-se de uma hipótese que sustenta haver uma idade ideal para a aquisição da língua. Estudos como o de Lennerberg (1967) e Pinker (1994) buscaram bases biológicas para sustentar que crianças têm idade determinada para aprender uma língua. O primeiro define essa fase entre 3 e 14 anos; e, o segundo, até os 6 anos. Outros preferem usar o termo "período sensível" (BYALISTOK e HAKUTA, 1999).

\section{Referências}

ALIANÇA CULTURAL BRASIL-JAPÃO. Relatório do I Simpósio de Ensino de Língua Japonesa. São Paulo. Relatório, 1979.

ALIANÇA CULTURAL BRASIL-JAPÃO Denshô e no michi: Burajiru shakai ga yôkyûsuru nihongo kyôiku to sono tenbô. ( $O$ caminho para a transmissão: o ensino de língua japonesa que a sociedade brasileira espera e os seus desdobramentos). São Paulo. Relatório, 1982.

BYALISTOK, E.; HAKUTA, K. Confounded Age: Linguistic and Cognitive Factors in Age Differences for Second Language Acquisition. In: BIRDSONG, D. (ed.), Second Language Acquisition and Critical Period Hypothesis. New Jersey: Lawrence Erlbaum Associates Inc., 1999, p. 161-181.

CUMMINS, J. Cross-linguistic dimensions of language proficiency: Implications for bilingual education and the optimal age issue. TESOL Quarterly, no 14, p. 81-103, 1980.

DOI, E. T. A presença japonesa no Brasil: a língua falada pela comunidade nipo-brasileira. Letterature D'America; Rivista Trimestrale. Roma, ano XXII, no 93-94, p. 19-36, 2002.

DOI, E. T. O ensino do japonês como língua da imigração. Estudos Lingüísticos XXXV, Campinas, 2006, p. 66-75.

DOI, E. T. Burajiru nikkeijn ni yotte hanasareru nihongo no bariêshon no kôsatsu. (Considerações sobre a variante japonesa falada por nikkeis no Brasil). In: Journal of the graduate school Kokugakuin University. Vol. 41. Kokugakuindaigaku Daigakuin. Japan: Tokyo, 2009, p. 115134.

ECKERT, P.; MCCONNELL-GINET, S. Think practically and look locally: language and gender as community-based practice. Annual Review of Anthropology, no 21, p. 461-490, oct. 1992.

FEDERAÇÃO DAS ESCOLAS DE ENSINO DE JAPONÊS NO BRASIL (org.). Ikusanga - Zenpaku Nichigo Kyôikushi (História do Ensino de Japonês no Brasil). São Paulo, 1966.

FUNDAÇÃO JAPÃO (2006). Diretório de instituições educacionais de língua japonesa do exterior. <http://www.jpf.go.jp/> Acesso em: 10 nov. 2007. 
JAPAN INTERNATIONAL COOPERATION AGENCY. Pesquisa sobre a situação atual das escolas japonesas voltadas aos filhos de imigrantes na América Latina e no Canadá. Relatório, 1986.

KAWAMURA, L. O processo educativo dos brasileiros no Japão. In: Pro-Posições, Campinas, v. 6, no 2[17], p. 64-84, jul. 1995.

KRASHEN, S. Principles and Practice in Second Language Acquisition. Oxford: Pergamon Press, 1982.

KUYAMA, M. O uso da língua japonesa na comunidade nipo-brasileira: o empréstimo lexical no japonês falado pelos imigrantes - o caso do Distrito Federal. Dissertação de mestrado. Universidade de São Paulo, São Paulo, 1999.

KUYAMA, M. Fatores sociais e frequência de empréstimos do português no japonês falado pelos imigrantes no Brasil - o caso do Distrito Federal. In: Revista Estudos Japoneses, São Paulo, no 20, p. 69-85, 2000.

LAVE, J.; WENGER, E. Situated Learning: Legitimate Peripherical Participation. Cambridge: Cambridge Univesity Press, 1991.

LENNERBERG, E. Biological foundations of language. New York: Wiley, 1967.

LIGHTBOWN, P. M. Exploring relationships between developmental and instructional sequences in L2 acquisition. In: SELIGER, H. \& LONG, M. H. (ed.) Classroom-oriented research in second language acquisition. Rowley, MA: Newbury House, 1983, p. 217-243.

LONG, M. H. Input, interaction and second language acquisition. In: WINITZ, H. (ed.) Native language and foreign language acquisition: Annual of the New York Academy of Science, no 379, 1980, p. 259-278.

MCMAHILL, C. The importance of Portuguese Language Education in Japan: a survey of Nikkei Returnee Students to Brasil. In: Keieironshû. Daito Bunka University, 2010, p. 133-149.

MORALES, L. M. Cem anos de imigração japonesa no Brasil: o ensino de japonês como língua estrangeira. Tese de doutoramento. Departamento de Linguística, Faculdade de Filosofia, Letras e Ciências Humanas. Universidade de São Paulo, 2009a.

MORALES, L. M. A diversidade na abordagem do ensino de língua japonesa no Brasil: raízes históricas e perfil geracional dos professores. In: Anais do XX Encontro Nacional de Professores Universitários de Língua, Literatura e Cultura Japonesa e VII Congresso Internacional de Estudos Japoneses no Brasil. USP, 2009b, p. 155-166.

MORALES, L. M. Professores bilíngues regressos do Japão: caso de bilíngues consecutivos de aquisição de japonês como L2 no contexto japonês. In: Proceedings of the Brazilian Studies Association. Tenth International Congress, 2010. CD-rom.

MORIYAMA, S. Gaikokugo kankyô de shûtoku ni eikyôsuru yôin no kôsatsu (Considerações sobre os fatores que influenciam a aquisição linguística em ambiente de língua estrangeira) In: SAKAMOTO et al. Tayôka suru gengo shûtoku kankyô to korekara no nihongo kyôiku ( $A$ diversificação do ambiente de aquisição lingüística e o futuro do ensino da língua japonesa), 2008, p.14-38.

MORIWAKI, R. Nihongo kyôiku no hensen (A transição da filosofia norteadora do ensino de língua japonesa - 1a. parte). In: Revista no 2, Centro de Estudos Nipo-Brasileiros, 1998, p. 71-85.

MORIWAKI, R. Nihongo kyôiku no hensen II (A transição da filosofia norteadora do ensino de língua japonesa - 2a parte). In: Revista no 4, Centro de Estudos Nipo-Brasileiros, 1999, p. 43-75.

PICA, T. Adult acquisition of English as a second language under different conditions of exposure. Language Learning, no 33, 1982, p. 465-497.

PINKER, S. The language instinct. New York: W. Morrow, 1994.

SHIBATA, Hiromi. As escolas japonesas paulistas (1915-1945): a afirmação de uma identidade étnica. Dissertação de mestrado. Faculdade de Educação da Universidade de São Paulo, 
São Paulo, 1997.

SOCIEDADE DE DIFUSÃO DA CULTURA NIPO-BRASILEIRA. Pesquisa sobre a situação atual das instituições de difusão do ensino no Brasil, 1977.

URANO, E. I. Um olhar sobre o trabalhador dekassegui. In: Travessia - Revista do Migrante. São Paulo, ano XV, no 43, p. 26-30, maio/ago. 2002.

YAMAMOTO, L. E. Mulheres imigrantes no Japão. In: Travessia - Revista do Migrante, São Paulo, ano XIV, no 41, p. 29-33, set./dez. 2001.

\title{
RESUMO
}

Este trabalho tem como objetivo trazer à tona a emergência de um novo grupo de professores de japonês, que são os brasileiros retornados do Japão, em consequência do fluxo migratório conhecido como decasségui. São pessoas que foram levadas para o Japão ainda em idade tenra, ou nasceram lá, e passaram pela educação escolar no país. Enquanto a maioria de descendentes jovens no Brasil não se interessa pela docência em língua japonesa, os retornados buscam tal ocupação justificando que "ensinar o japonês é a única coisa que sabem fazer". Diante da escassez de pessoas fluentes no idioma em quatro habilidades lingüísticas, e também da demanda reprimida de professores dessa língua no Brasil, esse novo perfil vem contribuir para a sua revitalização. A pesquisa analisou, qualitativamente, o relato de três informantes, tendo em vista o seu histórico de migração, nos seguintes aspectos: nível de bilinguismo, circunstâncias de aquisição e aprendizagem das duas línguas (japonês e português), motivações pessoais, além do desempenho linguístico.

Palavras-chave: bilinguismo; decasségui; formação de professores.

\begin{abstract}
This work aims at bringing to light the emergence of a new group of Japanese teachers who are Brazilians that have returned from Japan with a school education in Japan, as a result of the migration flow known as dekasegi. They are people that when children were taken to Japan at an early age, or were born there and went through Japanese Educational system. While most young descendants in Brazil are not interested in teaching the Japanese language, returnees searching for justify this choice by saying that "teaching Japanese is the only thing they know how to do." Given the short supply of people fluent in the language, an unmet demand for teachers of this language in Brazil, these new profiles have come to contribute to language revitalization. The research examined qualitatively the profile of three informants, in view of their migration history concerning the following items: level of bilingualism, circumstances of acquisition and learning of the two languages (Japanese and Portuguese), personal motivations, as well as language performance.
\end{abstract}

Keywords: bilingualism; dekasegi; teacher training. 